\title{
Equity in focus: Iqaluit water contaminated, tuberculosis on the rise, blood ban easing
}

\author{
— Cite as: CMAJ 2021 November 8;193:E1706-7. doi: 10.1503/cmaj.1095970
}

Posted on cmajnews.com on October 19, 2021

$\mathbf{N}$ unavut declared a local state of emergency in Iqaluit after tests confirmed "exceedingly high" concentrations of fuel in the water supply.

Iqaluit's mayor warned the city's 8000 residents against drinking tap water even after boiling.

Qikiqtani General Hospital - the only hospital in the city and territory - will perform only emergency surgeries until the risks posed by the contamination are clearer. The hospital is using single-use medical instruments wherever possible.

According to Nunavut's chief public health officer Dr. Michael Patterson, high concentrations of fuel in the water could make it difficult for health care workers to wash their hands properly and dangerous to sterilize medical instruments in a steam autoclave.

Iqaluit residents first reported a fuel smell coming from local tap water early in October, and some experienced headaches and vomiting after drinking the water.

Recent testing identified high levels of various fuel components in an underground tank at Iqaluit's water treatment plant, but no other contaminants of concern. According to Patterson, "The risk of long-term health effects is not a concern at this point."

The plant has sealed off the tank from the rest of the water supply, and city workers are flushing the waterlines. The Nunavut government has been flying in shipments of potable water, and food centres have added water delivery to their services, while many residents have collected water from a nearby river. The origin of the contamination remains unknown.
Rachel Blais, who runs a local food bank, said the situation in Iqaluit is the latest in a long list of predominantly Indigenous communities without safe drinking water, where boil-water advisories have become the norm.

In other health equity news:

- Tuberculosis (TB) deaths are on the rise again for the first time in more than a decade, according to the World Health Organization. More than 1.5 million people died from TB in 2020, compared to 1.4 million in 2019, while fewer people received TB diagnoses or preventive treatment owing to health service disruptions caused by the COVID-19 pandemic. Low- and middle-income countries accounted for most of the deaths, and the World Health Organization (WHO) predicts the toll will continue to rise in 2021 and 2022. "This is alarming news that must serve as a global wake-up call to the urgent need for investments and innovation to close the gaps in diagnosis, treatment and care," said WHO Director-General Tedros Adhanom Ghebreyesus.

- TB also appears to be resurging in some parts of Canada. Saskatchewan recently declared an outbreak in two northern First Nations communities involving more than a dozen confirmed cases and hundreds of potential contacts. Preliminary data suggest the number of TB infections in the province rose from 64 in 2019 to 100 in 2020 - the first increase in years. According to the Athabasca Health Authority, "Given that the COVID-19 crisis is ongoing... TB crisis manage- ment may potentially suffer some setbacks if not given the needed attention."

- Canadian Blood Services announced it will allow gay and bisexual men to donate plasma in a new pilot program, partially lifting a ban that many have criticized as discriminatory. Men who have sex with men will now be eligible to donate plasma in Calgary and London, provided they have not had a new sexual partner in the last three months and their existing partners have not had sex with other people. However, these new criteria don't appear to apply to other potential donors, and men who have had sex with men in the past three months still cannot donate blood. According to Dr. Graham Sher, CEO of Canadian Blood Services, the new policy is a step toward using "sexual behaviourbased screening for all donors."

- Experiencing adversities like abuse, neglect and poverty in childhood is associated with elevated risk for chronic disease, including heart disease and cancer, according to research in JAMA Pediatrics. Researchers reviewed 19 meta-analyses and found that childhood adversity accounted for more than 439000 deaths annually in the United States and $15 \%$ of US deaths in 2019. Experiencing adversity in childhood was also associated with one in three suicide attempts and millions of sexually transmitted infections annually, as well as illicit drug use, smoking, physical inactivity, and elevated inflammation later on in life. 
- Gay and bisexual men are advocating for the off-label use of the meningitis vaccine Bexsero to prevent gonorrhea, citing a 2017 study that found it lowered the risk of acquiring the sexually transmitted infection by more than $30 \%$. While the vaccine is recommended for people at high risk of meningococcal disease, the manufacturer advises against off-label use. According to Dr. Troy Grennan, physician lead for the HIV/STI program at the BC Centre for the Disease Control, gonorrhea and meningococcal disease are caused by related bacteria. There are a couple of ongoing studies into the use of Bexsero to prevent gonorrhea, and some doctors are already administering the vaccine to men who have sex with men.

- Medical providers and laypeople are better at discerning authentic pain in the expressions of white people than in Black people, according to research in Social Psychological and Personality Science. Researchers showed 904 medical providers and laypeople videos of white and Black people expressing real and feigned pain and found that both white and Black participants were better at identifying real pain in white people. "We argue this sensitivity deficit could be a contributing factor in racial disparities in pain care," said Dr. E. Paige Lloyd of the University of Denver.

\section{Greg Basky, Saskatoon, Sask.}

Content licence: This is an Open Access article distributed in accordance with the terms of the Creative Commons Attribution (CC BY-NC-ND 4.0) licence, which permits use, distribution and reproduction in any medium, provided that the original publication is properly cited, the use is noncommercial (i.e., research or educational use), and no modifications or adaptations are made. See: https://creativecommons. org/licenses/by-nc-nd/4.0/ 